\title{
The Development of Time-Series Based Outage Distribution Models For Feeder Lines In South Western Nigeria
}

\author{
${ }^{1}$ Megbowon, Israel Olu. and ${ }^{2}$ Oyeyemi, G. M. \\ ${ }^{I}$ Department of Electronic ond Electrical Engineering \\ Bells University of Technology, ota, Ogun State, Nigeria \\ ${ }^{2}$ Department of Statistics University of Ilorin, Ilorin, Nigeria
}

\begin{abstract}
This paper reports the development of a Time-Series based outage forecast model on electrical power distribution feeder lines in the Molete District of the network of the Power Holding Company of Nigeria $(\mathrm{PHCN})$ within the city of Ibadan in Nigeria.

A five-year(1999-2003) monthly outage data (in hours per month) gathered on the feeder lines was analyzed with the Time-series analysis program in the statistical software package Systat to generate the autocorrelation and the model parameters. These parameters are: smoothing coefficient, Trend coefficient, seasonality index and standard error of the forecast. The models were developed using the parameters. The models were then used to obtain a 24-month outage forecast figures and plots for each of the ten feeder lines.

The results indicate that seasonal factors influenced the monthly outage on the feeder lines with the forecast figures rising to their peaks within the rainny season months of June to August while the minimum forecast figures occur during the dry season period which is from November to February on each feeder line. The outage hours on the feeder lines increased with the lengths of the lines with the outage forecast figures rising to as much as 392 hours per month and 328 hours per month respectively on CRIN and Ring-Road, the two longest feeder lines, in the rain season while they were as low as 51.6 hours per month and 64.77 hours per month respectively on Black-House and Best-Oil, the two shortest feeder lines within the same period.
\end{abstract}

Key Words: - Distribution feeder lines, time-series, autocorrelation plots, autoregressive moving average (ARMA), model parameters, monthly outage forecast models.

\section{INTRODUCTION}

A time-series is a sequence of data ordered in time and often obtained at uniform intervals of time. A time-series data also exhibits a statistical dependence which is expressed in its autocorrelation [8]. Time-series technique has been used for decades for prediction and forecasting and the process involves the fundamental assumption that past patterns will tend to repeat in the future[3] Although variations do occur and past patterns do not always occur exactly, time-series forecasting has proved to be a useful and effective tool in planning. Forecasting is actually a transformation about past events in a system into future projections and is therefore a very popular means of predicting future performance in systems.

\section{TIME-SERIES FORECASTING MODELS}

In any form of forecasting,. accurate models are a sine-qua-non. Time-series model development involves the determination of the structural components of the series. These structural components are: trend coefficient, seasonality index, cyclic variation, irregular components and smoothing coefficient.

The trend component indicates the overall variation of the series over time. They are typically modeled as linear which assumes a constant rate of increase or decrease over time or quadratic which assumes a rate of change that is either increasing or decreasing.

A trend model is generally of the form

$$
\mathrm{F}(\mathrm{t})=\mathrm{B}_{\mathrm{o}}+\mathrm{B}_{1} \mathrm{t}
$$

where $\mathrm{F}(\mathrm{t})$ is the forecast for time $t$ and $\mathrm{B}_{0}, \mathrm{~B}_{1}$ are the model parameters.

Seasonal components are either monthly or quarterly variations whose pattern is repeated every year. Seasonal components are estimated using dummy variable regression model which has 0 or 1 values for each of the time periods during the year.

A quarterly model has the form:

$$
\mathrm{F}(\mathrm{t})=\mathrm{B}_{0}+\sum_{j=2}^{4} B X_{j}
$$


where $F(t)$ is the time-series value for period $t$

$\mathrm{B}_{0}$ is the series mean

The $\mathrm{B}_{\mathrm{j}}$ 's are the estimated seasonal adjustments

and the $\mathrm{X}_{\mathrm{jt}}$ 's are 1 for quarter $\mathrm{j}$ and 0 for other quarters.

The model for monthly data has the form

$$
\mathrm{F}(\mathrm{t})=\mathrm{B}_{0}+\sum_{j=2}^{12} B X_{j}
$$

Cyclic components represent an effect that moves repeatedly from high to low levels over the time interval. They are characterized by their amplitudes and periods required to move from high to low values and return.

One form of cyclical model is given by:

$$
\begin{array}{r}
\mathrm{F}(\mathrm{t})=\mathrm{B}_{0}+\mathrm{B}_{1} \text { Sinwt }+\mathrm{B}_{2} \text { Coswt } \\
\text { where } \mathrm{w}=\frac{2 \pi}{p}
\end{array}
$$

$\mathrm{P}$ is the period and $\mathrm{B}_{1}, \mathrm{~B}_{2}$ are the amplitudes. The Bi's are the parameters.

When the structural components (trend, seasonal and cyclical) have been used to estimate the values of a time-series, the observed differences between the forecast and the actual values constitute the irregular components.

Smoothing is the general term used for the methods of estimating the values of irregular components of a time-series and exponential smoothing is one of these methods.

The Standard Error, SE, gives a measure of the variability of the forecast value and the means of specifying the lower and upper bounds of the forecast. The upper and lower bounds are given by

$$
\text { Upper (Lower) bound }=\text { Forecast value } \pm z_{\alpha / 2} \mathrm{SE} \text {, }
$$

where $z_{\alpha / 2}$ is obtained from standard normal table at the confidence level $\alpha$.

\section{BOX-JEKINS METHODOLOGY}

Box-Jekins methodology is a comprehensive method of developing time-series forecasting models and is based on three basic models, viz: Moving Average(MA) model, Autoregressive(AR) model and the Mixed autoregressive moving Average(AMAR) model. The latter being a hybrid of the first two [2 ].

The Moving Average model assumes that the current value of the time-series data can be expressed as a linear combination of previous forecast errors[1] and when the time-series data is best described by a Moving Average (MA) model , the theoretical autocorrelation exhibits large spikes.

In Autoregressive(AR) model, the assumption is that the series can be expressed as a linear combination of previous values of the times-series and an unexplained portion. The application of this model is indicated when the autocorrelation exhibits a decaying pattern of an exponentially oscillating or sine function[3]. The application of the mixed model is indicated when both the sample autocorrelation and the sample partial autocorrelation exhibits a decaying pattern.

\section{THE NIGERIAN ELECTRIC POWER SYSTEM PERFORMANCE}

The performance of the Nigerian Electric power system most unfortunately is nothing to write home about. A World Bank study[9] reported the extremely low reliability of the system between 1980 and 1990. Among other details, the report mentioned forced outages, service curtailments and damaging voltage fluctuations as daily expe[riences during the period. It also reported a total of 22 total system collapse incidents, 11 major partial system faults and innumerable localized interruptions in 1987 alone. The report attributed the problems to inadequate availability of generating capacity, frequent failures of transmission and distribution facilities. The report concluded that in both financial and operational performances, the Nigerian Electric power system performed "dismally".

That was the situation more than two decades ago. The situation today is hardly better except that there has been a decline in the frequency of system collapse[5]. A measure of unbundling was introduced to decentralize the management of the Nigerian electric power system in the bid to improve its performance. The impact of that change is yet to be seen to date.

A study[4] carried out on the southwestern axis of the system between 1999 and 2003, reported transmission line availability of $96.14 \%$, a distribution feeder line availability of $93 \%$ and a distribution feeder line failure rate of 0.029 failures per hour. The installed generating capacity has remained at $6,130 \mathrm{MW}$ while the actual generation is 2,763.6 MW[6] for a population that is greater than one hundred million. 
Yet the literature is filled with abundant evidences that the economic growth of any nation is directly related to power availability and power consumption. According to Uwaifor [10] a country is today recognized as a third world country if, by general acts of omission or commission it is unable to supply safe, qualitative and reliable electrical power to its populace as and when needed and therefore contributes to the suppression of their socio economic development. It has been shown that there is a bidirectional relationship between energy consumption and economic growth in Nigeria.

Onohaebi[7] found out that the Nigerian transmission system is characterized by prolonged and frequent outages due to equipment ageing and poor maintenace among other factors. This is the situationin the transmission section which is expected to perform better than the distribution section.

This study aims at developing a time-series based monthly outage forecast model which can be used to predict monthly outage on a given feeder line. With such information it will be possible to estimate the amount of public utility energy that may be available on a particular feeder line within any given month for an industrial production process or commercial activity.

\section{MATERIALS AND METHODS}

A five-year (1999 - 2003) monthly outage data was obtained on ten distribution feeder lines sampled for study in Molete district of the Power Holding Company of Nigeria(PHCN). This District now falls into the newly created Ibadan Distribution Zone. The ten feeder lines and their parameters are shown in Table 1.0. The monthly outage data on each of the ten feeder lines sampled were analyzed using the time-series analysis program in the statistical software package SYSTAT. The software produced the autocorrelation plots of the monthly outage data on each of the feeder lines. They are shown in Figures 1.0 - 10.0

Each of the plots is an exponentially damped sine wave indicating the presence of random fluctuations with an underlying probability distribution whose central tendency decreases with time

The pattern of the plots suggests that a combination of autoregressive model and exponential smoothing model is the most suitable for forecasting the data. This combined

feature is obtainable in the mixed Autoregressive Moving Average (ARMA) model. The software was also used to generate the parameters of this model from the outage data. The ARMA forecast model is of the form.

$$
\mathrm{F}(\mathrm{t})=\mathrm{K}_{\mathrm{o}}+\mathrm{K}_{\mathrm{s}}+\mathrm{K}_{\mathrm{r}} \mathrm{t}
$$

where $F(t)$ is the outage forecast for the forecast month $t$.

$\mathrm{K}_{\mathrm{o}}$ is the final smoothing coefficient

$\mathrm{K}_{\mathrm{s}}$ is the final seasonality index for each of the twelve months of the year and

$\mathrm{K}_{\mathrm{r}}$ is the trend parameter.

\section{ANALYSIS AND RESULTS}

The seasonality indices for the various months on each of the feeder lines are shown in Table 2 . The smoothed values and the trend parameters are given in Table 4 together with the outage models in terms of the seasonality index, $\mathrm{K}_{\mathrm{s}}$, and forecast month, $\mathrm{t}$ from equation (1). The standard error of the forecast is given in Table 3.

\section{24-MONTH FORECAST FOR OSOSAMI AND THE OTHER FEEDER LINES}

As an example, the outage forecast for Ososami feeder line is obtained as follows: The model for Ososami feeder line, from Table 4 is given by

$$
\mathrm{F}(\mathrm{t})=149.112+\mathrm{K}_{\mathrm{S}}+0.864 \mathrm{t}
$$

From Table 2, and for the month of January $2004, \mathrm{~K}_{\mathrm{s}}=5.318, \mathrm{t}=1$ (one month after the study period)

$$
\therefore \mathrm{F}(\mathrm{t})=149.112+5.318+0.864(1)=155.294
$$

The 24 - month (January, 2004 to December, 2005) forecast for the ten feeder lines were similarly obtained and plotted as shown in Figure 11.0.

\section{DISCUSSIONS ON OUTAGE FORECAST MODEL}

The analysis of the data indicates seasonal effects with each month having a seasonal -ity index as indicated in Table 2. Positive seasonality indices indicate that the prevailing factors in the month or season tend to increase outage hours while negative seasonality indices indicate that the prevailing factors in the seasons or months cause outage hours to decrease.

From the results of the analysis, the month with highest positive seasonality index is July followed by August and June. These are the months of heavy rainfall. It can be inferred therefore that the heavy rainfalls and the accompanying factors are among the factors which increase outage problems on the feeder lines.

In the same vein, the months with highest negative seasonality indices are November, December and January. These are the months of generally clear weather. It may be inferred therefore that fine weather contributes to the reduction of outage incidence on the feeder lines. 
The analysis indicate positive (worsening) outage trends on seven out of the ten feeder lines studied in Molete district, while the remaining three exhibit negative (improving) outage trends. From the analysis, Ring Road feeder line shows the highest positive trend with a trend parameter of 4.33. Ring Road is followed by CRIN, Oke-Ado, 7-Up and Ososami with trend values of 2.312, 1.54, 1.256 and 0.864 respectively. The situation on these feeder lines requires that steps be taken to change the trend from positive to negative values.

Black - House, Best - Oil and Eagle Flour feeder lines exhibit negative (decreasing) outage trends with trend parameters of $-1.776,-0.64$ and -0.477 respectively. Efforts still need to be made to cause the monthly outage levels to decrease faster.

Figure1 shows the forecast plots of the monthly outage hours on the ten feeder lines . The forecast origin is December 2003, the last month of the study period and the forecast period is from January 2004 to December 2005.

The forecast plots on the different feeder lines show similar patterns of variation throughout the forecast period with the highest forecast values occurring in the months of June, July and August while the lowest values occur in the months of December, January and February. These periods of maximum and minimum outage forecast coincide with the months of highest and lowest seasonality indices on the different feeder lines. It can be inferred therefore that seasonal factors have much effect on the overall outage hour figures. This deduction suggests that a lot of preparation should be made at the approach of the rain season to attend to outage problems.

The forecast plots indicate that the outage forecast on Black-House, Best-Oil and Eagle-Flour feeder lines are very low between November and March. In particular the outage forecast on Black-House becomes negative during the period. This situation follows the low (actually negative) seasonal indices of these months as well as the negative trend parameters of the feeder lines which indicate decreasing outage with time. It means that if the negative trend continues, there would be a time when no outage will occur on the feeder lines during each of the low outage months.

A closer look at the forecast figures indicates that they vary with the lengths of the feeder lines. For instance, available data shown in Table 1, indicates that Black-House, Best-Oil and Eagle-Flour feeder lines are some of the shortest with lengths 4.0 kilometers, 3.0 kilometers and 3.0 kilometers respectively while CRIN, Oke-Ado and Ososami are the longest with lengths 44.7 kilometers, 19.7 kilometers and 13.3 kilometers respectively. These longest feeder lines have some of the highest outage forecasts. CRIN in particular has the highest outage for all months while the shortest feeder lines, Black-House, Best-Oil and Eagle-Flour feeder lines have the lowest forecast figures for all months of the year.

\section{CONCLUSION}

The results indicate that seasonal factors which come with the rains increase monthly outage hours of the feeder lines. They also indicate that longer lines have higher monthly outage hours than shorter ones. This is in addition to the generally known fact that long lines are prone to low voltage problems at their remote ends. Reduction of feeder line lengths will therefore contribute to availability in the distribution network.

Additionally, in order to minimize monthly outage hours on the feeders efforts need to be made to reinforce the feeders against seasonal factors at the approach of the rains and to make enough men, tools, equipment and materials readily available for maintenance purposes during the season. This will reduce the logistics time component of the total down time.

\section{REFERENCES}

[1]. Adejumobi, I.A. (2005): An Assessment of Distribution System Reliability Using Time-Series, International Journal of Engineering and Engineering Technology Vol.4, No 1, pp. 1 - 9.

[2]. Box, G. E. P. and Jenkins, G. M (1969) Time-Series Analysis forecasting and control, Revised Edition, Holden - Day Publishers.

[3]. Mabert, V.A (1978) An introduction to short term forecasting using the Box-Jenkins methodology. . Production Planning and Control Division, American Institute of Industrial Engineers, Inc. Publication No 2 in the Monograph series.

[4]. Megbowon, I.O.(2009) A Reliability Assessment of the Transmission and Distribution Systems of the Electrical Power System in Southwestern Nigeria. Ph.D Thesis, School of Postgraduate Studies, Federal University of Technology, Akure, Nigeria.

[5]. NCC (2005) Generation And Transmission Grid Operations. 2005 Annual Technical Report.of the National Control Center of the Power Holding Company of Nigeria.(PHCN).

[6]. Nnanna, O.J. ; Editor-In-Chief (2004) Electricity Generation and Consumption, Central Bank of Nigeria Statistical Bulletin, Vol. 15 P. 280. 
[7]. Onohaebi, O.S. (2009) Power outages in the Nigerian Transmission Grid; Research Journal of Applied Sciences Vol. 4 No 1; Pp $1-9$

[8]. Pandit, S. M. and Wu, S. (1983) Time - Series Analysis with Applications, John Wiley and Sons Inc,

[9]. Schram, G. (1990) Electric Power in Developing Countries: Status, Problems, Prospects; AnnualReview of Energy, Vol. 15. Pp.307 - 333.

[10]. Uwaifor, S.O (1992) Electric power distribution planning and development. Millhouse press Limited. Lagos, Nigeria

TABLE 1.0: PARAMETERS OF FEEDER LINES

\begin{tabular}{|c|c|c|c|c|c|c|}
\hline $\mathrm{SN}$ & $\begin{array}{l}\text { NAME OF } \\
\text { FEEDER. }\end{array}$ & $\begin{array}{l}\text { VOLTAGE } \\
\text { LEVEL }(\mathrm{kV})\end{array}$ & $\begin{array}{c}\text { LENGTH } \\
\text { (KMO) }\end{array}$ & $\begin{array}{c}\text { FROM } \\
\text { (SOURCE) }\end{array}$ & TO (TERMINAL) & $\begin{array}{l}\text { LOAD } \\
(\mathrm{AWW})\end{array}$ \\
\hline 1 & OSOSANI & 11 & 133 & OLUYOLE & FELELE & 27.6 \\
\hline 2 & RNG-ROAD & 11 & 113 & . & BADAN GRAM & 47.4 \\
\hline 3 & OKE-ADO & 11 & 19.7 & . & MCOLETE & 48.8 \\
\hline 4 & 7-UP & 11 & 118 & & OLUYOLE EXT & 40.4 \\
\hline 5 & CHALLENGE & 11 & 9 & $\begin{array}{c}\text { TNIERCHANG } \\
\text { E }\end{array}$ & FELELE & 39 \\
\hline 6 & ORIN & 11 & 44.7 & & ALAHO & 56 \\
\hline 7 & BYE-PASS & 11 & 6 & 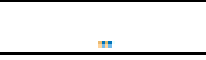 & PODO VILLAGE & 423 \\
\hline 8 & BLACK-HORSE & 11 & 4 & ( & BLACK HORSE & 9.1 \\
\hline 9 & BEST-OIL & 11 & 3 & . & BESTOIL & 8.5 \\
\hline 10 & EAGLE-FLOUR. & 11 & 3 & & EAGLE FLOUR & 74 \\
\hline
\end{tabular}

TABLE 2: FINAL VALUES OF SEASONAL INDICES ON FEEDER LINES

\begin{tabular}{|l|l|l|l|l|l|l|l|l|l|l|}
\hline MONT & OSOSAMI & RROAD & O/ADO & $7-$ UP & CHALLENG & CRIN & BPASS & B HOUSE & B OIL & EFLOUR \\
\hline JAN & 5.318 & -24.22 & -51.159 & -51.119 & -25.622 & -60.462 & -42.86 & -23.88 & -16.45 & -20.454 \\
\hline FEB & 2.703 & -4.054 & -9.366 & -5.332 & 7.918 & -7.153 & -2.244 & -21.281 & -10.06 & -13.903 \\
\hline MAR & 17.221 & 20.784 & 22.999 & 20.241 & 30.81 & 15.852 & 22.359 & -15.547 & -1.202 & -7.866 \\
\hline APR & 23.933 & 24.961 & 30.787 & 31.706 & 47.283 & 21.095 & 44.618 & 0.137 & 8.116 & -1.557 \\
\hline MAY & 8.876 & 68.138 & 45.493 & 34.297 & 41.357 & 39.524 & 54.206 & 14.388 & 16.673 & 7.189 \\
\hline JUN & 23.022 & 76.529 & 55.106 & 40.829 & 35.333 & 52.729 & 57.229 & 23.617 & 18.064 & 17.314 \\
\hline JUL & 26.596 & 71.15 & 66.273 & 57.327 & 20.868 & 69.762 & 54.427 & 24.844 & 26.569 & 28.135 \\
\hline AUG & 35.314 & 63.198 & 66.501 & 47.231 & 34.041 & 62.95 & 31.533 & 24.11 & 19.51 & 27.988 \\
\hline SEP & 13.726 & 25.971 & 21.918 & 22.559 & 5.023 & 35.096 & -0.669 & 14.209 & 2.907 & 13.226 \\
\hline OCT & -11.919 & -53.985 & -41.303 & -24.827 & -38.177 & -26.887 & -49.01 & -2.955 & -16.29 & -6.076 \\
\hline NOV & -11.919 & -115.62 & -97.26 & -75.579 & -81.343 & -91.778 & -82.51 & -18.857 & -26.85 & -21.44 \\
\hline DEC & -77.619 & -108.70 & -102.64 & -93.267 & -78.195 & -102.44 & -86.53 & -25.637 & -23.31 & -25.174 \\
\hline
\end{tabular}

TABLE 3.0: STANDARD ERROR (SE) OF THE MONTHLY FORECASTS

\begin{tabular}{|c|c|c|c|c|c|c|c|c|l|}
\hline OSOSAMII & RROA & OKE-ADO & 7.UP & CHALLENGE & CRIN & BPASS & B HOUSE & B OIL & EFLOUR \\
\hline 32.769 & 37.796 & 23.396 & 42.67 & 47.17 & 38.78 & 19.138 & 10.411 & 13.16 & 8.827 \\
\hline
\end{tabular}


TABLE 4:PARAMETERS OF THE OUTAGE MODELS OF THE FEEDERS

\begin{tabular}{|c|l|c|c|l|}
\hline S/N & FEEDER LINE & $\begin{array}{l}\text { SMOOTHING } \\
\text { VALUE }\left(\mathrm{K}_{\mathrm{o}}\right)\end{array}$ & $\begin{array}{c}\text { TREND } \\
\text { PARAMETER }\left(\mathrm{K}_{\mathrm{r}}\right)\end{array}$ & $\begin{array}{l}\text { OUTAGE MODEL } \\
\mathrm{F}(\mathrm{t})=\mathrm{K}_{\mathrm{o}}+\mathrm{K}_{\mathrm{s}}+\mathrm{K}_{\mathrm{r} * \mathrm{t}}\end{array}$ \\
\hline 1 & OSOSAMI & 149.112 & 0.864 & $\mathrm{~F}(\mathrm{t})=149.112+\mathrm{K}_{\mathrm{S}}+0.864 \mathrm{t}$ \\
\hline 2 & RING ROAD & 226.69 & 4.33 & $\mathrm{~F}(\mathrm{t})=226.69+\mathrm{K}_{\mathrm{S}}+4.33 \mathrm{t}$ \\
\hline 3 & OKE-ADO & 251.448 & 1.514 & $\mathrm{~F}(\mathrm{t})=251.448+\mathrm{KS}+1.514 \mathrm{t}$ \\
\hline 4 & 7-UP & 243.112 & 1.256 & $\mathrm{~F}(\mathrm{t})=243.112+\mathrm{K}_{\mathrm{S}}+1.256 \mathrm{t}$ \\
\hline 5 & CHALLENGE & 251.376 & 0.295 & $\mathrm{~F}(\mathrm{t})=251.376+\mathrm{K}_{\mathrm{S}}+0.295 \mathrm{t}$ \\
\hline 6 & CRIN & 306.074 & 2.312 & $\mathrm{~F}(\mathrm{t})=306.074+\mathrm{K}_{\mathrm{S}}+2.312 \mathrm{t}$ \\
\hline 7 & BYE-PASS & 213.255 & 0.093 & $\mathrm{~F}(\mathrm{t})=213.255+\mathrm{K}_{\mathrm{S}}+0.093 \mathrm{t}$ \\
\hline 8 & BLACK HOUSE & 39.21 & -1.776 & $\mathrm{~F}(\mathrm{t})=39.210+\mathrm{K}_{\mathrm{S}}-1.776 \mathrm{t}$ \\
\hline 9 & BEST OIL & 42.727 & -0.646 & $\mathrm{~F}(\mathrm{t})=42.727+\mathrm{K}_{\mathrm{S}}-0.646 \mathrm{t}$ \\
\hline 10 & EAGLE FLOUR & 46.919 & -0.477 & $\mathrm{~F}(\mathrm{t})=46.919+\mathrm{K}_{\mathrm{S}}-0.477 \mathrm{t}$ \\
\hline
\end{tabular}

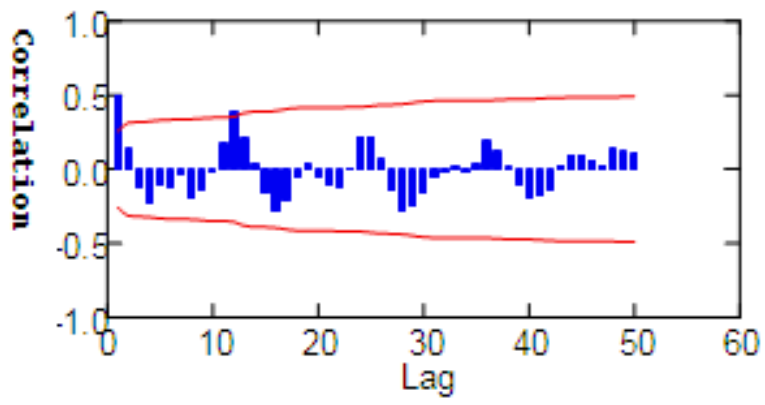

FIG.1.0: AUTOCORRELATION PLOT OF OSOSAMI FEEDER LINE

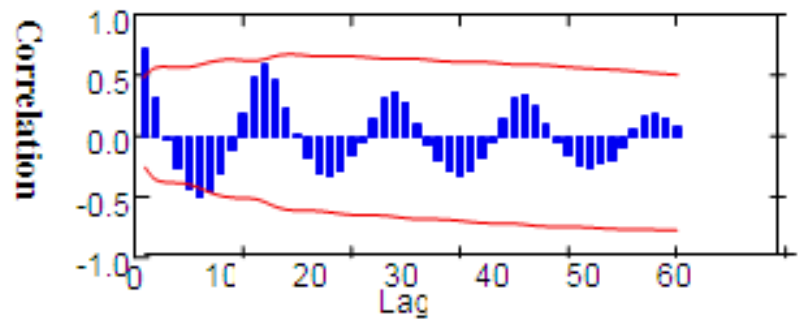

FIG.2.0:AUTOCORRELATION PLOT OF RINGROAD FEEDER LINE

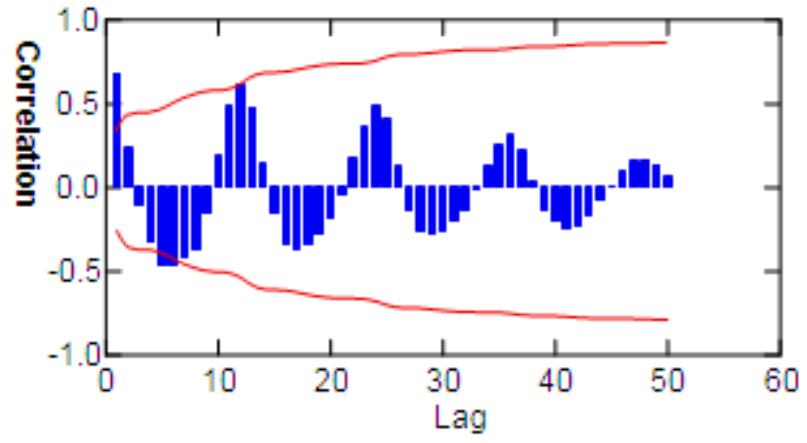

FIG.3.0: AUTOCORRELATION PLOT OF OKE-ADO FEEDER LINE 


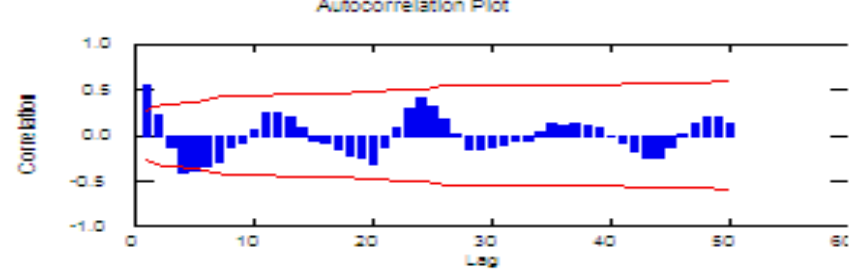

FIG.4.0: AUTOCORRELATION PLOT OF SEVEN-UP FEEDER LINE

Autocorrelation Plot

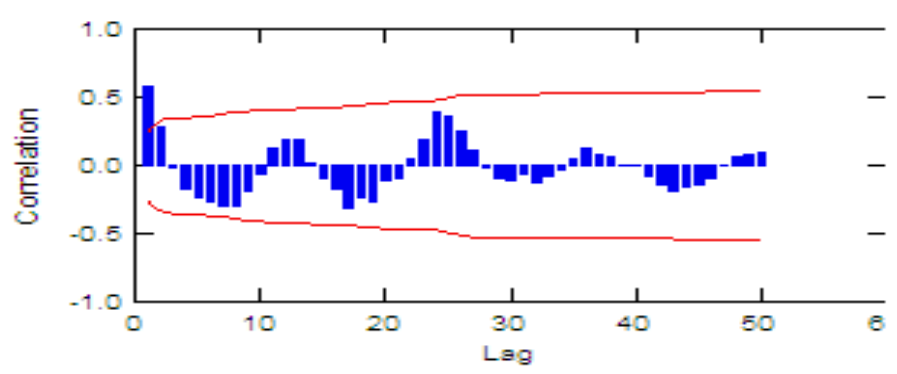

FIG. 5.0: AUTOCORRELATION PLOT OF CHALLENGE FEEDER LINE

Autocorrelation Plot

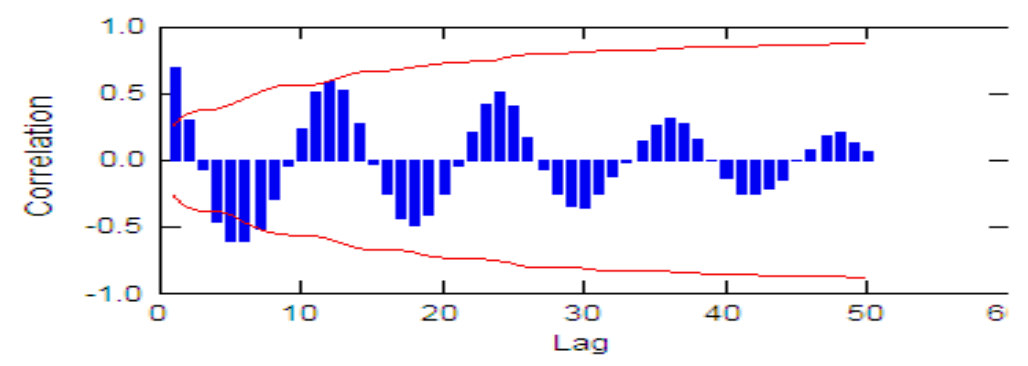

FIG. 6.0: AUTOCORRELATION PLOT OF CHALLENGE FEEDER LINE

Autocorrelation Plot

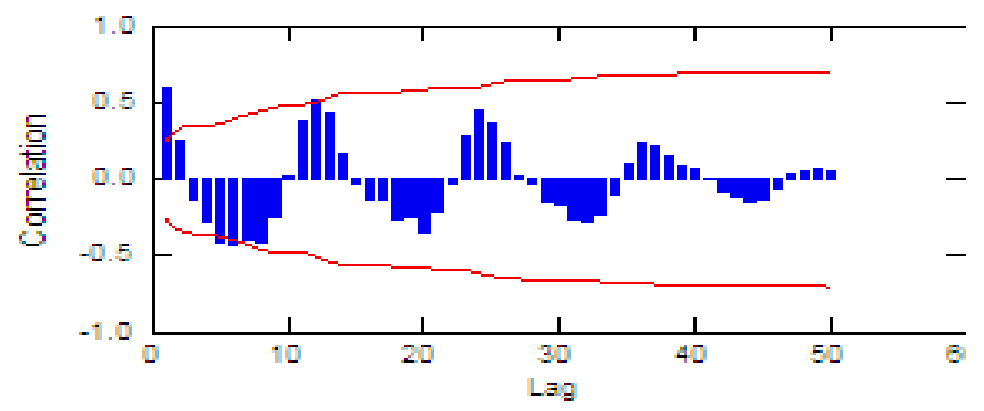

FIG. 7.0: AUTOCORRELATION PLOT OF CRIN FEEDER LINE

Autocorrelation Plot

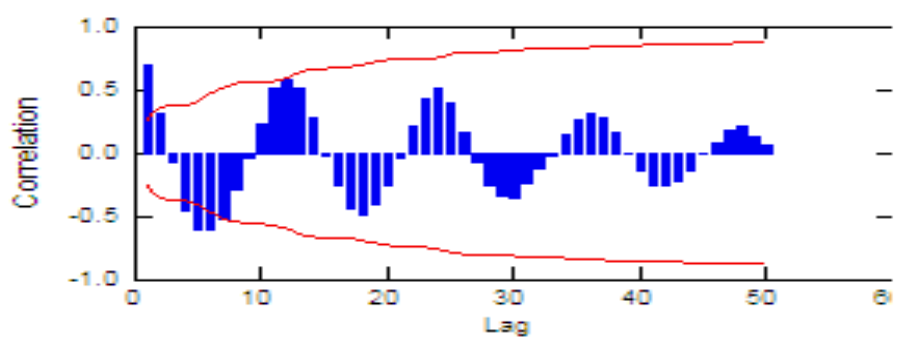

FIG. 8.0: AUTOCORRELATION PLOT OF BYE-PASS FEEDER LINE 


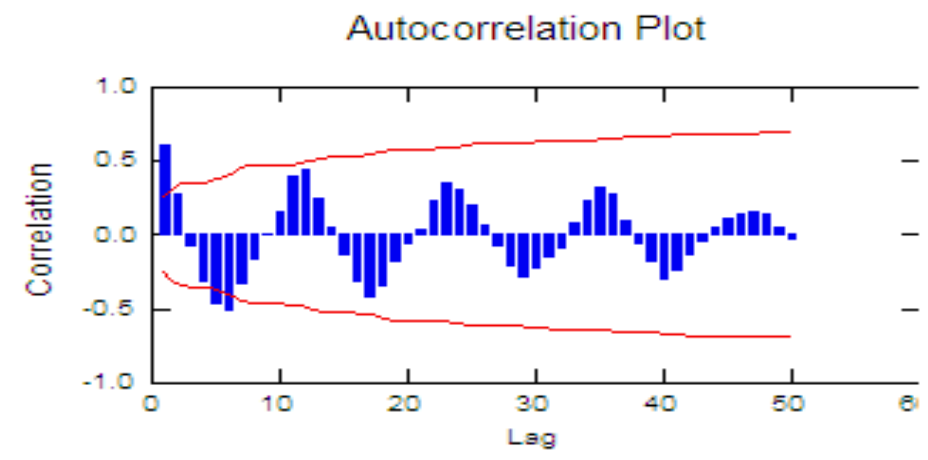

FIG.9.0: AUTOCORRELATION PLOT OF BEST-OIL FEEDER LINE

Autocorrelation Plot

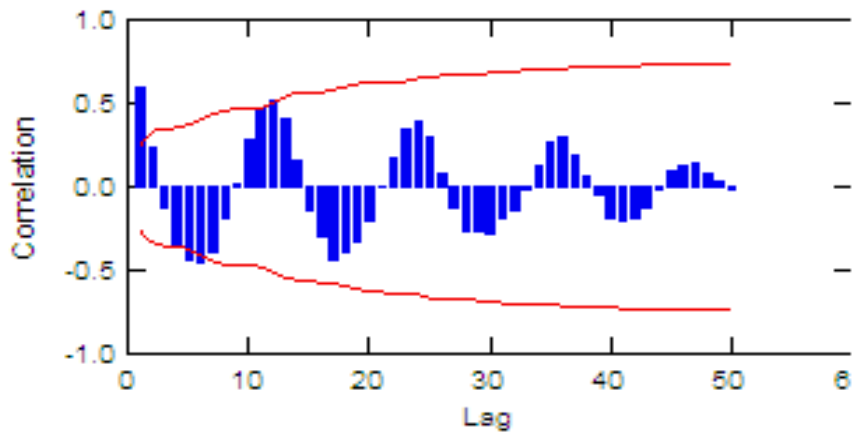

FIG.10.0: AUTOCORRELATION PLOT OF EAGLE-FLOUR FEEDER LINE

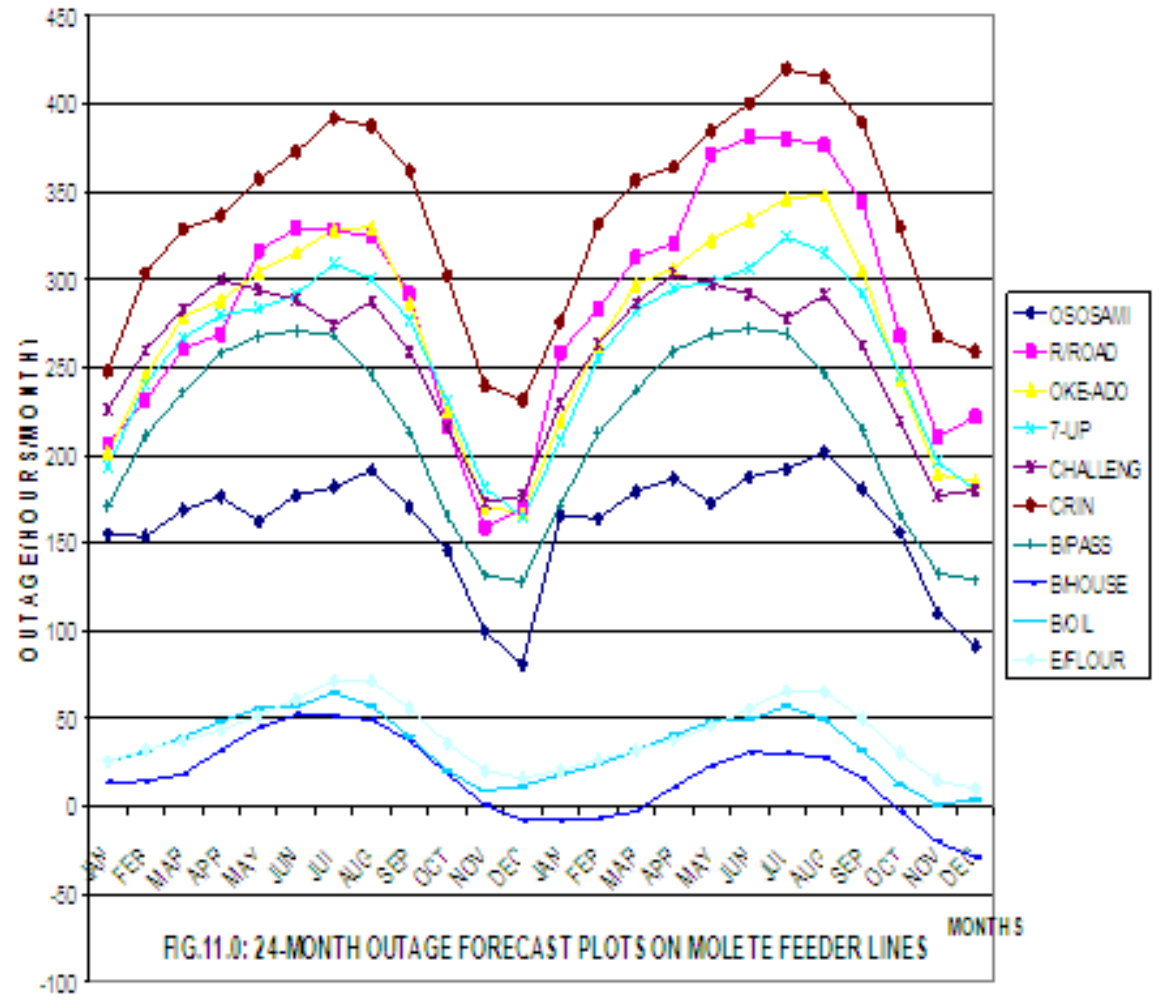

